\title{
Comparing Different Metadata Application Profiles for Agricultural Learning Repositories
}

\author{
Nikos Manouselis , Gauri Salokhe , Johannes Keizer
}

\begin{abstract}
Agricultural learning repositories can provide new opportunities for sharing, accessing, using and reusing learning resources online. Metadata plays a crucial role in such systems: apart from simply indexing resources, metadata makes it easier to discover a learning resource in a repository, as well as to decide about ways to use it for teaching or learning purposes. In the context of agricultural education and training, a variety of appropriate metadata standards may be selected, adapted and implemented for a learning repository. In this paper we introduce the concept of metadata for agricultural learning resources, and compare two particular cases: one application profile based on the Dublin Core Metadata Element Set (DCMES) and the other based on the IEEE Learning Object Metadata (LOM). The paper attempts to identify similarities and differences between the two case studies and to outline issues that have to be resolved in order to harmonize such efforts.
\end{abstract}

\section{Introduction}

The rapid evolution of Information and Communication Technologies (ICT) creates numerous opportunities for providing new services for education and training. Internet increasingly becomes a dominant medium for making resources available online in a digital format, in order to be accessed, used and reused by interested

\footnotetext{
Nikos Manouselis

Informatics Laboratory, Agricultural University of Athens, 75 Iera Odos Str., 11855, Athens, Greece, e-mail: nikosm@ieee.org

Gauri.Salokhe, Johannes.Keizer

Food and Agriculture Organization of the United Nations, Viale d. Terme di Caracalla, 00153 Rome, Italy e-mail: gauri.salokhe@fao.org

Johannes.Keizer

Food and Agriculture Organization of the United Nations, Viale d. Terme di Caracalla, 00153 Rome, Italy e-mail: johannes.keizer@fao.org
} 
audiences. In education and training, the central paradigm of this reuse-oriented technology is the notion of learning resources (sometimes referred to as learning objects) as reusable pieces of digital content. Very often learning resources are organized in learning repositories (LRs), which are systems for the storage, location and retrieval of content. In LRs, resources are being described using appropriate metadata that helps users discover them online and decide if/how they can put these resources into new educational uses.

Thus, in the education and training context, metadata interoperability has been judged as an essential issue. It allows the exchange and preservation of crucial learning and teaching information (such as competency profiles, learning activities, and descriptions of learning resources), as well as its future reuse among a large number of different systems and repositories. Recent standardization and specification efforts in the area of learning technologies have contributed to this direction. At the level of sharing, exchanging and reusing learning resources among different Learning Management Systems (LMS) and Learning Repositories (LRs), learning technologies aim to preserve a high level of interoperability by implementing relevant standards and specifications such as the Institute of Electrical and Electronics Engineers Learning Object Metadata (IEEE LOM [6]), Dublin Core (DC [4]) and its educational element set, and the recently introduced ISO Metadata for Learning Resources (ISO/IEC MLR [8]).

On the other hand, in the field of agricultural education and training, learning technologies' specifications and standards have not yet been widely adopted. Few initiatives have reported implementing them, and in most cases only to describe learning resources by using IEEE LOM or DC. In addition, efforts until now have been distributed and dispersed, leaving space to approaches with significant differences between them. This paper attempts to report such an experience from two initiatives that used different metadata standards for describing agricultural learning resources. It aims to identify commonalities and variations in the two approaches, and in this way gives interesting feedback to other implementers. Overall, this could serve as an initial step towards a potential harmonization of similar/competing approaches as far as the implementation of learning technologies in agricultural education and training applications is concerned.

More specifically, the paper examines how two widely accepted metadata standards (DC and IEEE LOM) have been used as the basis for the development of specialized metadata that will describe agricultural learning resources in two different application domains. The concept of metadata application profiles is introduced, representative related work on application profiles for agricultural learning resources is described, and then the two particular case studies are presented. Finally, based on a comparison of the two schemas, an identification of major similarities and differences is attempted in order to outline a number of issues that have to be resolved so as to bring closer such initiatives in the future and facilitate information sharing. 


\section{Background}

Metadata is usually termed as 'data about data' or 'information about information' $[11,14]$. It is generally engaged for describing the properties of information resources, in order to facilitate their categorization, storage, search and retrieval in digital collections. If metadata is stored in a structured and standardized manner, it may generally support the automation of search and retrieval mechanisms, the comparison between descriptions of different resources, the reusability of descriptions in different applications, as well as the interoperability between different storage systems. Metadata is made up of data items that are associated to the resource, the socalled metadata elements. Metadata schemas (or metadata models) are sets of metadata elements designed for a specific purpose, such as describing a particular type of resource [11]. Metadata specifications are well-defined and widely agreed metadata schemas that are expected to be adopted by the majority of implementers in a particular domain or industry. When a specification is widely recognized and adopted by some standardization organization, it then becomes a metadata standard.

Despite the existence of numerous metadata standards, there is no one allencompassing one to be used in every application. Rather, there are various metadata standards or specifications that can be adapted or "profiled" to meet community context-specific needs [9]. This conclusion has lead to the emergence of the application profile concept. An application profile (AP) is an assemblage of metadata elements selected from one or more metadata schemas, and its purpose is to adapt or combine existing schemas into a package that is tailored to the functional requirements of a particular application, while retaining interoperability with the original base schemas [5].

Many institutions are currently engaged in developing LRs that can be searchable and accessible for wider audience [16]. In this context, metadata plays an important role, since it makes access to the learning resources faster, easier and more effective. Towards this direction, standardization efforts around the world such as the IEEE Learning Technology Standards Committee ${ }^{4}$ (IEEE LTSC), the Education Working Group of the DC metadata initiative ${ }^{5}$, and ISO's sub-committee on Information Technology for Learning, Education and Training6 (ISO/IEC JTC1 SC36) have focused on the study and implementation of metadata element sets for describing learning resources, based on existing standards such as IEEE LOM and DC. Using such recognized metadata standards is important for a variety of reasons: metadata descriptions (records) of learning resources may be exchanged among different LRs; search queries may be propagated among different (and interconnected) LRs; and generally the integration of data from different sources is facilitated. For instance, this is the reason behind the extensive implementation and study of numerous APs of the LOM standard in LRs around the world [16, 7].

\footnotetext{
${ }^{4}$ http://ieeeltsc.org/

${ }^{5}$ http://www.dublincore.org/

${ }^{6}$ http://jtc1sc36.org/
} 


\section{Metadata for agricultural learning resources}

There have been several interesting approaches in creating metadata sets (or APs) for describing learning resources for the education and training of agricultural or rural stakeholders using the IEEE LOM. For instance, the CG LOM Core [18] has been created by the Consultative Group on International Agricultural Research (CGIAR) in order to describe its learning resources in a manner that best suits the content, purpose and audience of CGIAR's Online Learning Resources project ${ }^{7}$. This involves the development of a LR that will support an international community of trainers, educators, researchers and learners in agriculture and natural resources management. CGIAR defined a core set of metadata elements that describes, documents and registers the CG learning object metadata core (which is termed as CG LOM Core). The goal of applying a shared set of core metadata elements is to allow the federated search of training related documents across all CGIAR centers, as well as to achieve interoperability across the centers and with external entities. Because most centers have based the metadata of their Web resources on DC, the CG LOM core also includes a mapping with the DC metadata element set.

Another interesting LOM AP is the one developed by the European e-Content project Bio@gro ${ }^{8}$ for information dissemination and increasing public awareness regarding organic agriculture. This was created in order to categorize online educational resources that are related to organic agriculture [2]. The Bio@gro LOM AP has adopted a number of LOM elements, appropriately selecting vocabularies of values in such a way that the metadata descriptions reflect the particularities of the application area (i.e. organic agriculture). It will also be used as a basis for the development of a revised AP for the description of learning resources for organic agriculture and agroecology in the context of the Organic.Edunet initiative ${ }^{9}$ [13].

A similar AP has been developed to support the Turkish Agricultural Learning Objects Repository (TrAgLor) [3]. The main objective of this multilingual repository is to store digital learning objects developed for agriculture, veterinary, food, environmental and forestry sciences as well as all other agriculture related basic and applied sciences. TrAgLor, which is still work in progress, has been designed and developed based on a LOM AP. At present, this is a LR promoted to faculties of agriculture, veterinary, food and forestry around Turkey, where resources are being contributed by academic staff and students.

Other initiatives implementing a LOM AP for their LRs have been developed in the general life sciences domain. A characteristic example is the Biosci Education Network (BEN) repository ${ }^{10}$. This has been funded by the American National Science Foundation's National science, mathematics, engineering and technology education (SMETE) Digital Library program, the American Association for the Advancement of Science (AAAS), as well as other professional societies and coalitions for biology education. A BEN metadata specification based on LOM has been developed [1], in

\footnotetext{
${ }^{7}$ http://learning.cgiar.org/

${ }^{8} \mathrm{http} / / /$ www.bioagro.gr

${ }^{9} \mathrm{http}: / /$ www.organic-edunet.eu

${ }^{10} \mathrm{http} / / / \mathrm{www}$.biosciednet.org/
} 
order to facilitate BEN partners in making their collections of online biological sciences teaching and learning resources searchable through the BEN repository site.

Apart from the LOM-based approaches, other schemas are also used for the description of learning resources. For instance, a recent survey indicated that although $54 \%$ of surveyed LRs use LOM-based metadata, approximately $22 \%$ use DC-based metadata [16]. In this paper, we explore two characteristic representatives of these different approaches for agricultural education and training, and attempt a comparison.

\section{Case studies}

The two case studies of this paper are two metadata APs for learning resources that have been presented during the Special Session on Agricultural Metadata and Semantics of the $2^{\text {nd }}$ International Conference on Metadata and Semantics Research (MTSR'07), which took place during October 2007 in Corfu, Greece ${ }^{11}$. These APs have been developed following different philosophies:

- The first one, the FAO Ag-LR AP, has been developed by the Food and Agriculture Organization (FAO) of the United Nations, and is based on DC. It aims to support its Capacity and Institution Building Portal, which provides structured access to information on FAO's capacity and institution building services and learning resources [15].

- The second has been developed by the Informatics Laboratory of the Agricultural University of Athens, Greece, and has been built upon LOM. It describes training resources for rural development in the context of the Rural-eGov project [10].

\subsection{FAO's Agricultural Learning Resources Application Profile}

The United Nations General Assembly (A/RES/59/250) recognizes the crucial role of capacity building for achieving the Millennium Development Goals and calls upon the United Nations organizations to increase their support to developing countries' own efforts [17]. Capacity and institution building is a core function of FAO. In order to provide structured access to FAO's agricultural learning resources and capacity and institution building services, the "Capacity and Institution Building Portal" (hereafter referred to as the CIB Portal) project was started in 2006. When completed, the CIB Portal will provide direct access to learning resources, such as training materials, guidelines, tool kits, available in any media, which are usable in or prepared in support of a learning process by which individuals, groups and organizations can enhance their skills, and develop associated knowledge, attitudes and values, to improve their performance and solve problems in order to achieve their objectives. It will also facilitate access by external users, as well as FAO staff, to the Organization's learning resources and services, thus enhancing member countries' capacities.

${ }^{11}$ http://www.mtsr.ionio.gr/ 
To ensure that the CIB Portal can be searched by users and to enable interoperability with other LRs, one of the core activities of this project was to design an AP which adheres to standard nomenclature to describe agricultural learning resources. An important consideration when developing the AP for FAO's agricultural learning resources was the conformance with existing standards so as to assure that metadata records can be shared with other repositories, especially with those providing agricultural learning resources. Although the tendency of most LRs is to use LOM as the basis schema, FAO decided to base its standard on DC, for two main reasons:

- A considerable amount of FAO's learning resources already have a metadata record in one of FAO's repositories. These resources are currently described using the AGRIS AP, which is based on DC and the Agricultural Metadata Element Set (AgMES) [12]. This specification is widely used by FAO and its partner organizations. To be able to reuse these records would imply immense costsavings, so an AP based on DC and AgMES was considered the optimal solution.

- Because the AP would be promoted to FAO's member countries, who wish to establish similar LRs, it was important to ensure that it would be easy to use and implement. Thus, it was also important to identify a balanced number of data elements to keep the metadata creation effort manageable and to ensure a high return on investment. An AP which uses the complete set of $76 \mathrm{LOM}$ elements was, therefore, not practical. A survey on the usage of LOM shows, that in practice most communities use only parts of the complete set [7].

Table 1 DC, AgMES, and LOM elements that have been further specialized in Ag-LR AP.

\begin{tabular}{c|c|c|c}
\hline Title & Description & Use in Ag-LR & Vocabulary \\
\hline $\begin{array}{c}\text { Subject } / \\
\text { FAO } \\
\text { categories }\end{array}$ & The topic of the resource. & $\begin{array}{c}\text { Focusing on the particular } \\
\text { subject categories of } \\
\text { interest to FAO. }\end{array}$ & $\begin{array}{c}\text { FAO Categories } \\
{[15]}\end{array}$ \\
\hline Type & $\begin{array}{c}\text { The nature or genre of the } \\
\text { resource. }\end{array}$ & $\begin{array}{c}\text { Using an AgMES-based } \\
\text { controlled vocabulary. }\end{array}$ & $\begin{array}{c}\text { Type } \\
\text { vocabulary [15] }\end{array}$ \\
\hline $\begin{array}{c}\text { Format }- \\
\text { Type }\end{array}$ & $\begin{array}{c}\text { The file format, physical } \\
\text { medium, or dimensions of the } \\
\text { resource. }\end{array}$ & $\begin{array}{c}\text { Using an AgMES-based } \\
\text { controlled vocabulary. }\end{array}$ & $\begin{array}{c}\text { Format } \\
\text { vocabulary [15] }\end{array}$ \\
\hline Relation & A related resource. & $\begin{array}{c}\text { Relating resource to the } \\
\text { collections it belongs to and } \\
\text { to its other translations. }\end{array}$ & $\begin{array}{c}\text { 'collections', } \\
\text { 'translations' }\end{array}$ \\
$\begin{array}{c}\text { Intended } \\
\text { End User } \\
\text { Role }\end{array}$ & $\begin{array}{c}\text { Principal user(s) for which } \\
\text { this resource was designed. }\end{array}$ & $\begin{array}{c}\text { Limiting original LOM } \\
\text { vocabulary to desired } \\
\text { values. }\end{array}$ & $\begin{array}{c}\text { Adapted version } \\
\text { of LOM's [15] }\end{array}$ \\
\hline
\end{tabular}

Given the above circumstances, the most cost effective solution in the case of FAO resources was to set up an exchange profile with Dublin Core, AgMES and LOM elements. The needs analysis and the evaluation of existing standards resulted in an Agricultural Learning Resource AP (Ag-LR AP) which is created by taking elements from DC, IEEE LOM and AgMES. Twelve elements were taken from the DC Metadata Element Set namespace. Additional, seven elements from LOM were added to fulfill the task of fully describing a "learning resource". 
Another requirement of describing FAO learning resources has also been the use of standard terminologies such as FAO's multilingual agricultural thesaurus AGROVOC ${ }^{12}$. To allow consistent description of the learning resources in the CIB Portal, it was important to provide the possibility to index resources using terms from the AGROVOC thesaurus. Therefore, elements from the AgMES, namely subject refinements and the possibility to explicitly indicate AGROVOC (or any other agricultural thesaurus) were included in the AP. This will allow FAO resources (learning and other types) to be searched simultaneously using the same keywords.

An overview of the elements of DC, LOM and AgMES that have been specialized for the needs of Ag-LR AP is presented in Table 1. The original description of each element as well as the way it has been used in Ag-LR AP are included. More details about the Ag-LR AP and its elements are available in Stuempel et al. [15] and via the Agricultural Information Management Standards (AIMS) Web site ${ }^{13}$.

Table 2 LOM elements that have been further specialized in ReGov LOM.

\begin{tabular}{lccc}
\hline Title & Description & Use in ReGov & Vocabulary \\
\hline Language & $\begin{array}{c}\text { The primary human } \\
\text { language(s) used within this } \\
\text { resource to communicate to } \\
\text { the intended user. }\end{array}$ & $\begin{array}{c}\text { As LOM, focus on } \\
\text { languages of Rural-eGov } \\
\text { regions. }\end{array}$ & ISO 639-2 \\
\hline Keyword & $\begin{array}{c}\text { Keyword or phrase describing } \\
\text { the topic of this resource. }\end{array}$ & $\begin{array}{c}\text { Resource classification } \\
\text { based on agricultural } \\
\text { subject category. }\end{array}$ & $\begin{array}{c}\text { AGRIS Subject } \\
\text { Categories }\end{array}$ \\
\hline Coverage & $\begin{array}{c}\text { Geography or region to which } \\
\text { this resource applies. }\end{array}$ & $\begin{array}{c}\text { Include coverage of specific } \\
\text { European regions. }\end{array}$ & $\begin{array}{c}\text { ISO - 3166-1 } \\
\text { and NUTS } \\
\text { Codes }\end{array}$ \\
\hline $\begin{array}{c}\text { Intended } \\
\text { Role }\end{array}$ & $\begin{array}{c}\text { Principal user(s) for which } \\
\text { this resource was designed, } \\
\text { most dominant first. }\end{array}$ & $\begin{array}{c}\text { Extending original } \\
\text { vocabulary with "vocational } \\
\text { learner". }\end{array}$ & $\begin{array}{c}\text { Adopted from } \\
\text { LOM }\end{array}$ \\
\hline Context & $\begin{array}{c}\text { The principal environment } \\
\text { within which the resource and } \\
\text { use of this resource is } \\
\text { intended to take place. }\end{array}$ & $\begin{array}{c}\text { Extending original } \\
\text { vocabulary with "vocational } \\
\text { training". }\end{array}$ & $\begin{array}{c}\text { Adopted from } \\
\text { LOM }\end{array}$ \\
\hline Language & $\begin{array}{c}\text { The human language used by } \\
\text { the typical intended user of } \\
\text { this resource. }\end{array}$ & $\begin{array}{c}\text { As IEEE LOM, focus on } \\
\text { languages of Rural-eGov } \\
\text { regions. }\end{array}$ & ISO 639-2 \\
\hline
\end{tabular}

\subsection{Rural e-Gov IEEE LOM Application Profile (ReGov LOM)}

Regional as well as centralized authorities around Europe develop and offer an increased variety of online public services, which may be particularly useful for agricultural professionals in rural areas. Nevertheless, a major barrier towards their

\footnotetext{
${ }^{12} \mathrm{http} / / / \mathrm{www}$. fao.org/aims/ag_intro.htm

${ }^{13} \mathrm{http}: / / \mathrm{www}$. fao.org/aims/

${ }^{14} \mathrm{http}: / /$ www.fao.org/scripts/agris/c-categ.htm

${ }^{15} \mathrm{http}: / /$ ec.europa.eu/comm/eurostat/ramon/nuts/codelist_en.cfm?list=nuts
} 
adoption has been identified to be the low degree of ICT penetration that is usually recorded in these areas. Addressing such shortcomings, a recently deployed initiative titled 'Rural-eGov: Training SMEs of Rural Areas in using e-Government Services' 16 focuses on SMEs in five European regions (namely Wales in UK, Brandenburg in Germany, Aegean islands in Greece, Koscierzyna community in Poland, and Moravske Toplice in Slovenia). It builds on relevant experience from similar initiatives and bases its training activities around an online point of reference (the Rural e-Gov Observatory) which rural SMEs can access to find relevant information and learning resources.

Through the Rural-eGov Observatory, agricultural professionals will be able to find digital training resources about how to reap maximum benefits from the use of eGovernment services that cover their region. Thus, the Observatory includes a LR with training resources for rural stakeholders. To facilitate interoperability with other LRs, it has been decided that the metadata to be used in this LR should be based on LOM. Since it was not possible to locate other LOM-based schemas that are particularly developed for training resources and rural SMEs, a new AP was judged necessary.

To facilitate searching, locating and downloading appropriate resources, the important characteristics of the Rural-eGov training resources had to be reflected in their metadata. Metadata records had to also be available in the language of the users (that is, multilingual descriptions will be necessary). Since LOM has been chosen as a basis, the new AP has been termed as the Rural-eGov LOM (or simply, ReGov LOM) AP. ReGov LOM adopts many of the LOM elements as they are recommended by the standard, but also specializes several of them in order to best match the needs of the particular LR. In Table 2, the elements that have been specialized for Rural-eGov are described.

\section{Comparison}

The following paragraphs compare the overall characteristics of the two APs and discuss issues related to their educational and agricultural aspects. On the long run, this comparison aims to identify a set of issues that have to be clarified in order for such APs to be developed in a harmonized manner.

The Ag-LR AP of FAO consists of 23 elements, 9 of which are mandatory (M), 13 optional (O) and 1 automatically created (A). On the other hand, ReGov LOM AP consists of 48 elements, 16 of which are mandatory (M), 21 optional $(\mathrm{O})$ and 11 automatically created (A). As it is expected, the Ag-LR AP seems to be considerably easier for metadata authors to complete, compared to ReGov LOM AP.

In Ag-LR AP, 8 elements are used for the representation of general resource properties, 4 for classification purposes, 7 to reflect educational properties, 2 to represent copyrights and cost (Rights, Cost) information, and 2 (Identifier, Relation) to facilitate archiving/accessing of related materials (including language versions). Similarly, in the ReGov LOM AP 15 elements are used for the representation of

${ }^{16} \mathrm{http://rural-egov.eu}$ 
resource properties, 6 for classification purposes, 14 to reflect educational properties, 3 to represent copyrights and cost information, and 15 to facilitate archiving/accessing a resource. We note that the major difference between the two APs is that the ReGov LOM uses significantly more elements to describe general properties (e.g. Duration), educational properties (e.g. Difficulty), and to facilitate archiving/accessing (e.g. the Meta-Metadata category). This observation illustrates clearly the intrinsic difference in the philosophy of the LOM and the DC standards.

The elements that may be used for educational purposes in FAO's Ag-LR AP are the following: Notes, Aggregation Level, Type, Intended End User Role, Context, Interactivity Level, and Typical Learning Time. All but the Notes and Type elements are purely from LOM, and may be mapped to the corresponding ones of ReGov LOM AP, which include: Aggregation Level, Interactivity Type, Learning Resource Type, Interactivity Level, Typical Age Range, Difficulty, Typical Learning Time, Intended End User Role, Context, Language (of the targeted learners). Ag-LR Type element is used in a similar manner as the Learning Resource Type, where as Notes is used as the Description sub-element of the Annotation category in ReGov LOM AP. Since most of the educational elements in both APs are optional, we could say that ReGov LOM provides the possibility to express educational properties in a richer manner. But on the other hand, this makes the process of authoring a full record more time consuming and complex for a metadata author who is not an expert in classifying learning resources.

It is also interesting to examine the choice of elements in the two APs to classify resources according to their agricultural characteristics, e.g. using an agricultural classification scheme or vocabulary. In FAO's Ag-LRM AP only two elements use such a scheme: Subject/FAO Categories and Subject/Keywords. Similarly, in ReGov LOM AP the following two elements engage some agriculture-related vocabulary for resource classification: Keyword and Coverage (which is expressed in terms of particular regions in each country).

Overall, we can say that the development of the two APs for describing agricultural learning resources reveals differences that are more related to the different philosophies of the base schemas (i.e. LOM and DC) rather than the way these two are specialized for agricultural education and training. The main difference is in the number of elements that the two APs use for the description of non-agricultural properties such as general, educational and archiving ones. On the contrary, both APs use between 4-6 elements for classification purposes. From these, two are appropriately specialized for categorization according to some agriculture-related taxonomy or thesaurus. These two are not the same though for each schema, since Ag-LR is using an enhanced Subject classification using FAO Categories and Keywords (e.g. from AGROVOC); whereas ReGov LOM is using Keywords from the AGRIS categories, as well as a Coverage classification that goes to the level of individual regions (NUTS regions codes). If a common way of using such elements could be found, so that they can be easily mapped to one another, metadata interoperability on agricultural elements would be greatly facilitated. 


\section{Conclusions}

The development of an appropriate metadata schema can greatly facilitate the search and retrieval tasks of the users that are accessing an online agricultural LR, and several initiatives have produced their own APs of popular metadata specifications or standards like DC and IEEE LOM. On the other hand, the adoption of standards that have such different philosophies, might lead to the development of APs that have important differences, and are, therefore, impossible to combine through simple mappings. The examination of these two case studies, the DC-based Ag-LR AP and the LOM-based ReGov LOM AP, has clearly illustrated this. But it has also been observed that both schemas represent agriculture-related properties of the resources (mostly for classification purposes) in a similar manner. Therefore, it seems reasonable to head first for some consensus about the way such elements are defined and used in APs for agricultural learning resources. Appropriate guidelines and/or best practices could be devised and suggested.

As far as the rest of the elements are concerned, our study indicated that they are generally used for purposes that seem to be closely linked to the needs of the application domain (e.g. archiving/accessing, educational, etc.). A more extended study of similar APs will reveal if any concurring patterns exist in the use of such systems in agricultural education and training initiatives, or if those elements should be treated depending on the application.

\section{Acknowledgments}

The authors would like to thank their colleagues from FAO and the Rural-eGov project that have contributed in the development of Ag-LR AP [15] and ReGov LOM AP [10], respectively.

\section{References}

1. BEN (2003) Biosci Education Network (BEN) Metadata Specification. AAAS for the Biosci Education Network Collaborative, Version 1.2.

2. Bio@gro (2005) Metadata Models for Bio@gro Content Objects (BCOs) Description. Bio@gro Technical Report.

3. Cebeci Z., Erdogan Y., Kara M. (2008) TrAgLor: A LOM-Based Digital Learning Objects Repository for Agriculture. In: Proc. of the 4th Int. Scientific Conference "eLearning and Software for Education (eLSE'08)". 17-18 April 2008, Bucharest, Romania.

4. DC (2004) Dublin Core Metadata Element Set, Version 1.1: Reference Description. Dublin Core Org.

5. Duval E, Hodgins W, Sutton S, Weibel SL (2002) Metadata Principles and Practicalities. D-Lib Magazine, 8. http://www.dlib.org/dlib/april02/weibel/04weibel.html. Accessed 18 January 2008.

6. IEEE LOM (2002) Draft Standard for Learning Object Metadata. IEEE Learning Technology Standards Committee, IEEE 1484.12.1-2002. 
7. ISO (2004) Final Report on the "International LOM Survey". ISO/IEC JTC1 SC36. http://jtc1sc36.org/doc/36N0871.pdf. Accessed 18 January 2008.

8. ISO/IEC (2005) Working Draft for ISO/IEC 19788-2 - Metadata for Learning Resources Part 2: Data Elements. ISO/IEC JTC1 SC36.

9. Kraan W (2003) No one standard will suit all. The Centre for Educational Technology Interoperability Standards. http://www.cetis.ac.uk/content/20030513175232. Accessed 18 January 2008.

10. Manouselis N, Kastrantas K, Tzikopoulos A (2007) An IEEE LOM application profile to describe training resources for agricultural and rural SMEs. In: Proc. of the 2nd International Conference on Metadata and Semantics Research (MTSR'07), Corfu, Greece.

11. NISO (2004) Understanding Metadata. National Information Standards Organisation, NISO Press.

12. Salokhe G, Onyancha I, Weinheimer J, Richards B, Le Hunte Ward F, Keizer J (2005) The AGRIS Application Profile for the International Information System on Agricultural Sciences and Technology. Food and Agriculture Organization of the United Nations, Italy. http://www.fao.org/docrep/008/ae909e/ae909e00.htm. Accessed 18 January 2008.

13. Sanchez-Alonso S, Sicilia M-A (2007) Using an AGROVOC-based ontology for the description of learning resources on organic agriculture. In: Proc. of the 2nd International Conference on Metadata and Semantics Research (MTSR'07), Corfu, Greece.

14. Steinacker A, Ghavam A, Steinmetz R (2001) Metadata Standards for Web-Based Resources. IEEE Multimedia, 70-76.

15. Stuempel H, Salokhe G, Aubert A, Keizer J, Nadeau A, Katz S, Rudgard S (2007) Metadata Application Profile for Agricultural Learning Resources. In: Proc. of the 2nd International Conference on Metadata and Semantics Research (MTSR'07), Corfu, Greece.

16. Tzikopoulos A, Manouselis N, Vuorikari R (2007) An Overview of Learning Object Repositories. In: Northrup P (ed) Learning Objects for Instruction: Design and Evaluation, Hershey, PA: Idea Group Publishing, 29-55.

17. UN (2005) Triennial comprehensive policy review of operational activities for development of the United Nations system (59/250). United Nations General Assembly: Resolution adopted by the General Assembly on the report of the Second Committee. http://daccessdds.un.org/doc/UNDOC/GEN/N04/491/26/PDF/N0449126.pdf. Accessed 18 January 2008.

18. Zschocke T, Paisley C, Duval E, Beniest J (2005) CG Learning Object Metadata (LOM) Core. CGIAR ICT/KM OLR Project. 